\title{
BMJ Open Low fasting glucose and future risks of major adverse outcomes in people without baseline diabetes or cardiovascular disease: a systematic review and meta-analysis
}

Hung-Wei Liao, ${ }^{1}$ Jeffrey Saver, ${ }^{2}$ Hsin-Chieh Yeh, ${ }^{3}$ Chi-Hsin Sally Chen, ${ }^{4}$ Yi-Ling Wu, ${ }^{5}$ Meng Lee, ${ }^{6}$ Bruce Ovbiagele ${ }^{7}$

To cite: Liao H-W, Saver J, Yeh $\mathrm{H}-\mathrm{C}$, et al. Low fasting glucose and future risks of major adverse outcomes in people without baseline diabetes or cardiovascular disease: a systematic review and meta-analysis. BMJ Open 2019;9:e026010. doi:10.1136/ bmjopen-2018-026010

- Prepublication history and additional material for this paper are available online. To view these files, please visit the journal online (http://dx.doi org/10.1136/bmjopen-2018026010).

Received 16 August 2018 Revised 30 May 2019 Accepted 13 June 2019

Check for updates

(C) Author(s) (or their employer(s)) 2019. Re-use permitted under CC BY-NC. No commercial re-use. See rights and permissions. Published by BMJ.

For numbered affiliations see end of article.

Correspondence to

Dr Meng Lee;

menglee5126@gmail.com

\section{ABSTRACT}

Objective To investigate the link between low fasting blood glucose levels and all-cause mortality and cardiovascular outcomes among people without baseline diabetes or cardiovascular disease.

Design Systematic review and meta-analysis.

Data sources PubMed and Embase (1966-February 2019). Selection criteria Prospective cohort studies were included for meta-analysis if they reported adjusted HRs with $95 \%$ Cls for associations between risk of all-cause mortality, stroke, major cardiovascular events, coronary heart disease and low fasting glucose levels $(<4.6 \mathrm{mmol} / \mathrm{L}$ and $/$ or $4.0 \mathrm{mmol} / \mathrm{L}$, respectively) versus normal fasting glucose levels.

Data extraction and statistical analysis Two independent reviewers extracted data from eligible studies. Heterogeneity was assessed by $p$ value of $\chi^{2}$ tests and $I^{2}$. We assessed four characteristics for each included study based on items developed by the US Preventive Task Force, as well as the modified checklist used in previous studies.

Results Eleven articles (consisting of 129 prospective cohort studies) with 2674882 participants without diabetes and cardiovascular disease at baseline were included in this meta-analysis. Pooled results from the random effects model showed increased risks of all-cause mortality (HR: $1.56 ; 95 \% \mathrm{Cl} 1.09$ to 2.23 ), total stroke (HR: $1.08,95 \% \mathrm{Cl} 1.03$ to 1.13) and ischaemic stroke (HR: $1.06,95 \% \mathrm{Cl} 1.01$ to 1.10 ), and major cardiovascular events (HR: $1.05,95 \% \mathrm{Cl} 1.03$ to 1.07) among people with a fasting glucose $<4.0 \mathrm{mmol} / \mathrm{L}$, as compared with people with normal fasting glucose. The less stringent low fasting glucose level, $<4.6 \mathrm{mmol} / \mathrm{L}$, was not associated with increased risk of any endpoints.

Discussion and conclusions Among people without baseline diabetes or cardiovascular disease, a fasting blood glucose level of $<4.0 \mathrm{mmol} / \mathrm{L}$ is associated with increased risk of all-cause mortality, major cardiovascular events and stroke.

\section{INTRODUCTION}

Elevated fasting blood glucose level is associated with higher risk of cardiovascular disease
Strengths and limitations of this study

- The size of this study and inclusion of only prospectively collected data strengthened the robustness of our findings.

- Although individuals in our meta-analysis were not diabetic patients with iatrogenic hypoglycaemia, the reason for the low concentrations of glucose in the low fasting blood glucose population was not established.

- About $5 \%$ of people without diabetes and cardiovascular disease at baseline have fasting glucose levels of $<4.0 \mathrm{mmol} / \mathrm{L}$ and these individuals harbour a $56 \%$ greater hazard of long-term all-cause mortality, as compared with individuals with a normal glucose level.

and mortality. ${ }^{1}$ Presence of diabetes mellitus or prediabetes have been related to greater risks of major adverse cardiac events, stroke and death. ${ }^{2-4}$ Since glucose is a necessary body nutrient, and blood glucose concentration is regulated by various hormones within a narrow range in the body, ${ }^{5}$ theoretically fasting blood glucose lower than a certain level may be also associated with harmful effects. In patients with diabetes, intensive glycaemic control increased mortality. ${ }^{6}$ In people without diabetes and cardiovascular disease at baseline, whether low fasting blood glucose levels affects outcomes is not well established. A link between low fasting blood glucose concentrations and higher risk of all-cause death was first observed in a long-term follow-up study, the Paris Prospective Study, ${ }^{7}$ which enrolled participants from 1967 to 1970. Moreover, people with low fasting blood glucose concentrations had higher occurrences of cardiovascular and all-cause mortality than normal 
reference groups. ${ }^{8}$ However, other studies have suggested that low fasting blood glucose is not associated with increased risks of major cardiovascular events. ${ }^{9}$ A major discrepancy between these various studies has been the definition of low fasting blood glucose, which ranged from $<3.9 \mathrm{mmol} / \mathrm{L}(70 \mathrm{mg} / \mathrm{dL})^{8}$ to $<4.9 \mathrm{mmol} / \mathrm{L}(88 \mathrm{mg}$ / dL). ${ }^{10}$

Although blood glucose level $\leq 3.9 \mathrm{mmol} / \mathrm{L}$ ( $70 \mathrm{mg}$ / $\mathrm{dL}$ ) has been proposed as hypoglycaemia in patients with diabetes receiving medical therapy, ${ }^{11}$ there has not been a consistent definition for low fasting blood glucose levels in people without diabetes, and the cut-off level has varied across studies.

Given the aforementioned issues and discrepancies, we set out to analyse low fasting blood glucose thresholds of $<4.6 \mathrm{mmol} / \mathrm{L}(83 \mathrm{mg} / \mathrm{dL})$ and $4.0 \mathrm{mmol} / \mathrm{L}(72 \mathrm{mg} /$ $\mathrm{dL}$ ), respectively, according to cut-off levels of endogenous adjustment to maintain glucose homeostasis. ${ }^{12-14}$ We then conducted a systematic review and meta-analysis to determine whether a link exists between low fasting blood glucose and future risks of all-cause mortality, major cardiovascular events, stroke and coronary heart disease in people without diabetes and cardiovascular disease at baseline and to quantify the magnitude of any existing relation.

\section{METHODS}

This meta-analysis was conducted in accordance with the recommendations of the Preferred Reporting Items for Systematic Reviews and Meta-Analyses (PRISMA) statement. $^{15}$

\section{Patient and public involvement}

Patients were not involved in the design and conception of this study.

\section{Search strategy}

We systematically searched PubMed and Embase for the period up to 20 February 2019 by using Medical Subject Headings (MeSH) terms and free text with detailed search strategy presented in online supplementary table 1. We restricted the search to studies in humans with filters provided by PubMed and Embase. There was no language restriction. We also reviewed the Introduction and Discussion sections of retrieved studies and of prior reviews to identify additional studies.

\section{Study selection and data abstraction}

We selected studies that met the following entry criteria: prospectively collected data within cohort studies or clinical trials; blood glucose evaluated at baseline; assessed all-cause mortality, stroke, major cardiovascular events, coronary heart disease or cardiovascular mortality as an endpoint during the follow-up period; intended follow-up of at least 1 year for all participants; and reported quantitative estimates of the multivariate adjusted HR and 95\% CI or SE for the log HR for future endpoints associated with baseline low fasting blood glucose. Low fasting blood glucose levels was defined as fasting glucose $<4.0 \mathrm{mmol} / \mathrm{L}$ and/or $<4.6 \mathrm{mmol} / \mathrm{L}$. The reference group (ie, normoglycaemia) included people with fasting blood glucose levels between $4.7 \mathrm{mmol} / \mathrm{L}$ and $5.6 \mathrm{mmol} / \mathrm{L}$. We excluded studies that used cross-sectional, case-control or retrospective cohort study approaches, that consisted mostly of participants diagnosed with major diseases such as cardiovascular disease, end-stage renal disease or cancer; that only reported unadjusted HR; that did not report 95\% CIs; that the low fasting blood glucose was caused by an antidiabetic drug; that the cut-off level of low fasting blood glucose was higher than the stringent level (ie, $4.6 \mathrm{mmol} / \mathrm{L}$ ) used in this meta-analysis; or that were duplicated. One investigator (ML) developed selection criteria and conducted the literature search. Two investigators (H-WL and C-HSC) assessed these criteria and abstracted data independently from eligible studies. Discrepancies were resolved by discussion with a third investigator $(\mathrm{BO})$ and by referencing the original report.

\section{Assessment of study quality}

We assessed the quality of eligible studies. Assessment was based on guidelines developed by the US Preventive Task Force as well as the modified checklist used in previous studies. ${ }^{16-18}$ We assessed four characteristics for each included study and presented it in online supplementary table 2 .

\section{Statistical analysis}

The primary outcome was HR of all-cause mortality in people with low fasting blood glucose levels versus normoglycaemia. Secondary outcomes were incidences of stroke (including ischaemic or haemorrhage stroke), coronary heart disease, major adverse cardiovascular events and cardiovascular mortality.

We used multivariate-adjusted outcome data (expressed as HRs and $95 \%$ CIs) for data analysis. In every study, we converted these values by using their natural logarithms and calculated SEs from these logarithmic numbers and their corresponding 95\% CIs. For the statistical analysis, we combined $\log$ HRs and SEs using the inverse variance approach. We used a random effect model and assessed heterogeneity by $\mathrm{p}$ value of $\chi^{2}$ tests. ${ }^{19} \mathrm{~A}$ fixed effect model was also used for comparison with the random effects model on the overall risk estimate. We conducted a trim and fill analysis for the primary outcome to evaluate potential systematic bias in studies, including publication bias. A sensitivity analysis was performed to explore the robustness of our results. We removed each study from the meta-analysis one at a time to identify any possible disproportionate influence on results. Reported $\mathrm{p}$ values were two sided, with significance set at less than 0.05 . Heterogeneity was assessed by $\mathrm{p}$ value of $\chi^{2}$ statistics and $\mathrm{I}^{2}$, which described the percentage of variability in the effect estimates due to heterogeneity rather than to chance. ${ }^{2021}$ Based on the suggestion of the Cochrane Collaboration, we regarded heterogeneity as possibly unimportant when 


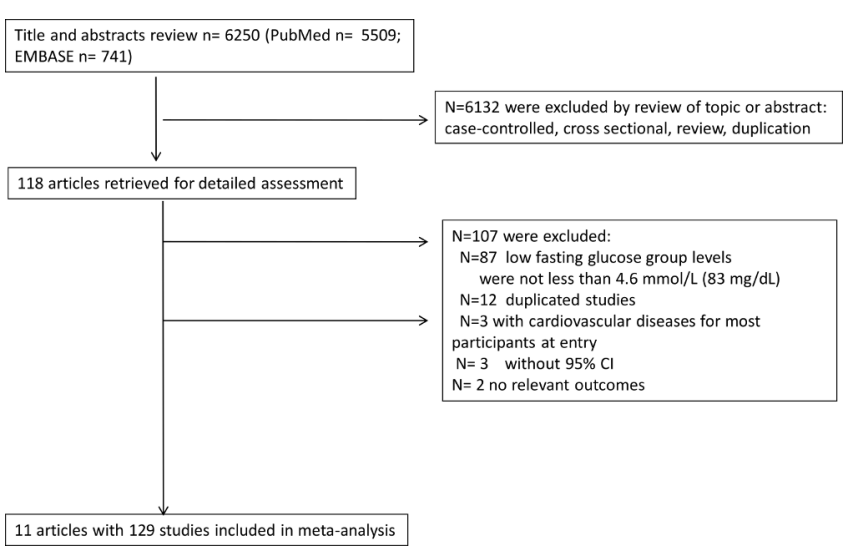

Figure 1 Flow chart of study selection.

the $\mathrm{I}^{2}$ value was less than $40 \%$ and considerable when more than $75 \% .{ }^{22}$ RevMan 5 was used for the meta-analysis of observational studies. ${ }^{3} 17$

\section{RESULTS}

The preliminary literature search identified 6250 articles, and after reviewing the abstracts and contents, 6132 articles were excluded, and the remaining 118 articles went through further detailed assessment. We used fasting blood glucose level $<4.6 \mathrm{mmol} / \mathrm{L}$ as cut-off to define low fasting glucose for retracting articles. Collaborative studies ${ }^{123-25}$ that analysed datasets from previous cohort studies were used, while the studies of those individual cohort were excluded in the current meta-analysis to avoid duplications. Finally, 11 articles with 129 studies were included for further analysis (figure 1). ${ }^{18923-30} \mathrm{~A}$ total of 2674882 individuals without diabetes mellitus and cardiovascular disease at baseline were enrolled in this meta-analysis. The mean age was 48 years and $32 \%$ were women. About $5.2 \%$ and $21.6 \%$ of individuals with their fasting glucose concentration of $<4.0 \mathrm{mmol} / \mathrm{L}$ and $<4.6 \mathrm{mmol} / \mathrm{L}$, respectively. The baseline characteristics of the included studies are summarised in table 1 . The number of participants in the included studies ranged from $2429^{29}$ to $1197384 .{ }^{28}$ The average follow-up duration was 14.3 years, ranging from 1 year to 20 years. In this meta-analysis, we used cut-off fasting glucose levels $<4.6$ and $<4.0 \mathrm{mmol} / \mathrm{L}$, respectively, for analysis. Seven articles reported cut-off fasting glucose level $<4.6 \mathrm{mmol} / \mathrm{L}^{18924-2629}$ and eight articles reported cut-off level of $<4.0 \mathrm{mmol} / \mathrm{L} .{ }^{1} 823-2527-29 \mathrm{In}$ Korean Cancer Prevention Study (KCPS) 2013 study, men and women data were separately analysed. ${ }^{28}$ Therefore, we analysed the data of men and women in KCPS 2013 study as independent data.

\section{Low fasting glucose and all-cause mortality}

In four articles using fasting glucose $<4.6 \mathrm{mmol} / \mathrm{L}$ as cut-off, the random effects summary estimate did not show increased risk of all-cause mortality after adjustment (HR: $1.17,95 \%$ CI 0.97 to $1.41 ; \mathrm{p}=0.10$ ) (figure 2). ${ }^{18925}$ We found evidence of heterogeneity across studies ( $p$ for heterogeneity $=0.0004, \mathrm{I}^{2}=77 \%$ ) but no major asymmetrical appearance in the funnel plot (online supplementary figure 1A). The estimate from a fixed-effects model (HR: $1.06,95 \%$ CI 1.00 to 1.13 ; $\mathrm{p}=0.06$ ) was similar to the estimate from a random-effects model.

In four articles using fasting glucose $<4.0 \mathrm{mmol} / \mathrm{L}$ as cut-off, the random effects summary estimate showed an increased risk of all-cause mortality after adjustment (HR: $1.56,95 \%$ CI 1.09 to 2.23; $\mathrm{p}=0.02$ ) (figure 2 ). ${ }^{182527}$ We found evidence of heterogeneity across studies ( $p$ for heterogeneity $=0.03, \mathrm{I}^{2}=67 \%$ ) and publication bias, with under-representation of small studies showing protective effects (online supplementary figure 1B). The estimate from a fixed-effects model (HR: 1.21, 95\% CI 1.09 to $1.34 ; \mathrm{p}=0.0003$ ) was smaller than the estimate from a random-effects model but still significant.

Sensitivity analyses excluding individual trials yielded pooled results that were not significantly different from the overall pooled estimates.

\section{Low fasting glucose and stroke}

In articles using fasting glucose $<4.6 \mathrm{mmol} / \mathrm{L}$ as cut-off, the random effects summary estimate did not show increased risks of total stroke (two articles; HR: 0.90, 95\% CI 0.64 to $1.28 ; \mathrm{p}=0.56$ ), ischaemic stroke (two articles; HR: $1.03,95 \%$ CI 0.94 to $1.12, \mathrm{p}=0.55)$ or haemorrhagic stroke (one article; HR: 0.98, 95\% CI 0.88 to 1.09 , $\mathrm{p}=0.71$ ).

In articles using fasting glucose $<4.0 \mathrm{mmol} / \mathrm{L}$ as cut-off, the random effects summary estimate showed increased risks of total stroke (one article with men and women reported separately; HR: 1.08 , 95\% CI 1.03 to 1.13 ; $\mathrm{p}=0.0006$ ) and ischaemic stroke (one article with men and women reported separately; HR: $1.06,95 \%$ CI 1.01 to $1.10 ; \mathrm{p}=0.02)$. Risk of haemorrhagic stroke was not significantly increased (two articles; HR: $1.16,95 \%$ CI 0.96 to $1.40 ; \mathrm{p}=0.11$ ) (figure 3).

Heterogeneity was difficult to assess for this pooled analysis involving three or fewer studies.

Low fasting glucose and major cardiovascular adverse events, coronary heart disease, and cardiovascular mortality

In articles using fasting glucose $<4.6 \mathrm{mmol} / \mathrm{L}$ as cut-off, the random effects summary estimate did not show increased risk of major adverse cardiovascular events (one article; HR: 0.96 , 95\% CI 0.77 to 1.20 ; $\mathrm{p}=0.72$ ), coronary heart disease (four articles; HR: $1.07,95 \%$ CI 0.94 to 1.21; $\mathrm{p}=0.31$ ) or cardiovascular mortality (three articles; HR: $1.26,95 \%$ CI 0.87 to $1.83 ; \mathrm{p}=0.23$ ).

In articles using fasting glucose $<4.0 \mathrm{mmol} / \mathrm{L}$ as cut-off, the random effects summary estimate showed increased risks of major adverse cardiovascular events (two articles; HR: 1.05 , $95 \%$ CI 1.03 to $1.07, \mathrm{p}<0.0001)$. Risks of coronary heart disease (three articles; HR: 1.02, 95\% CI 0.95 to $1.10 ; \mathrm{p}=0.61$ ) or cardiovascular mortality (three articles; HR: $1.47,95 \%$ CI 0.88 to $2.44 ; \mathrm{p}=0.14$ ) were not significantly increased (figure 4).

Heterogeneity was difficult to assess for this pooled analysis involving three or fewer studies. 


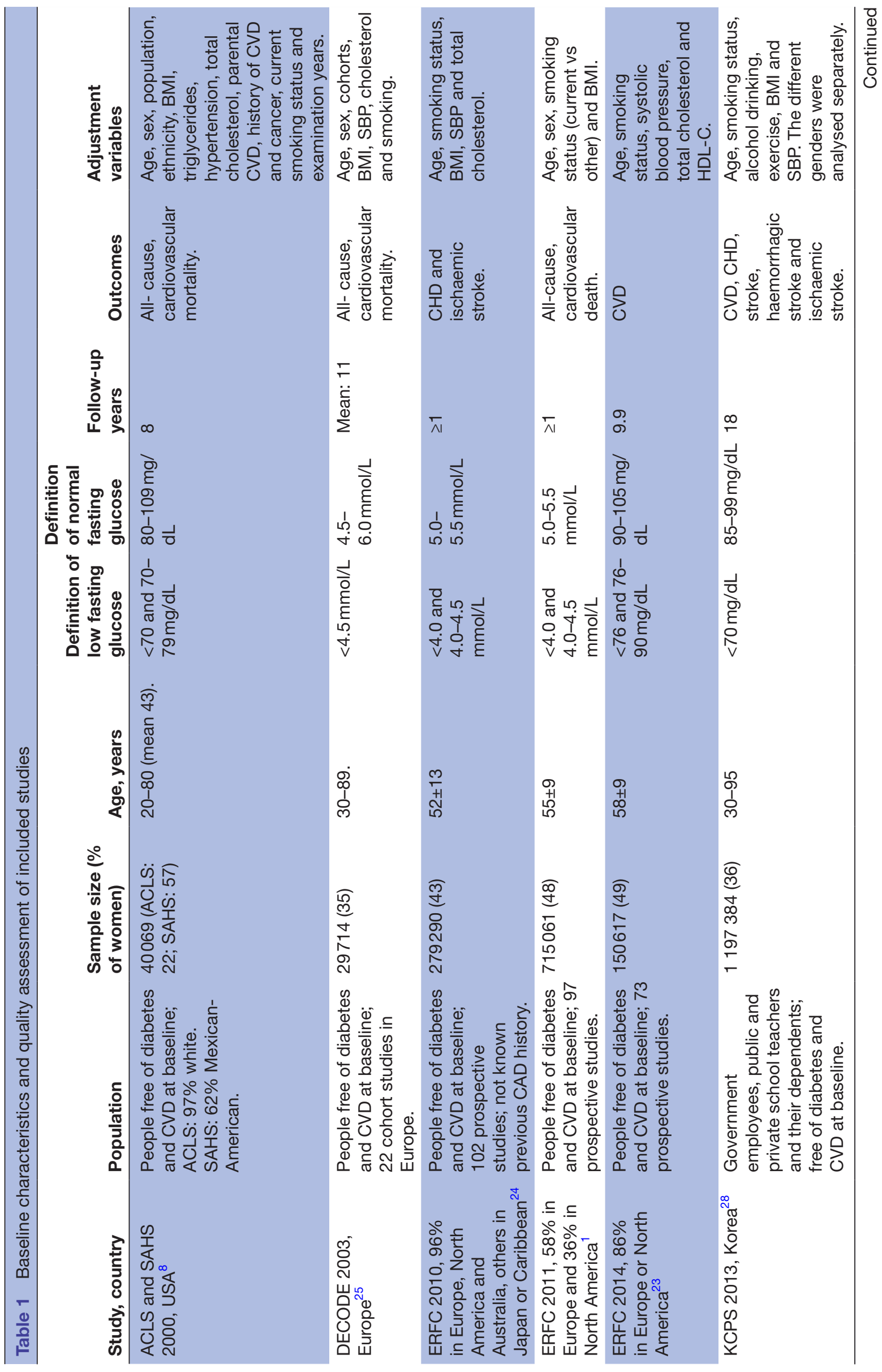

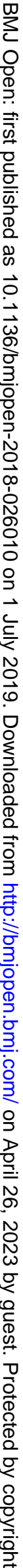




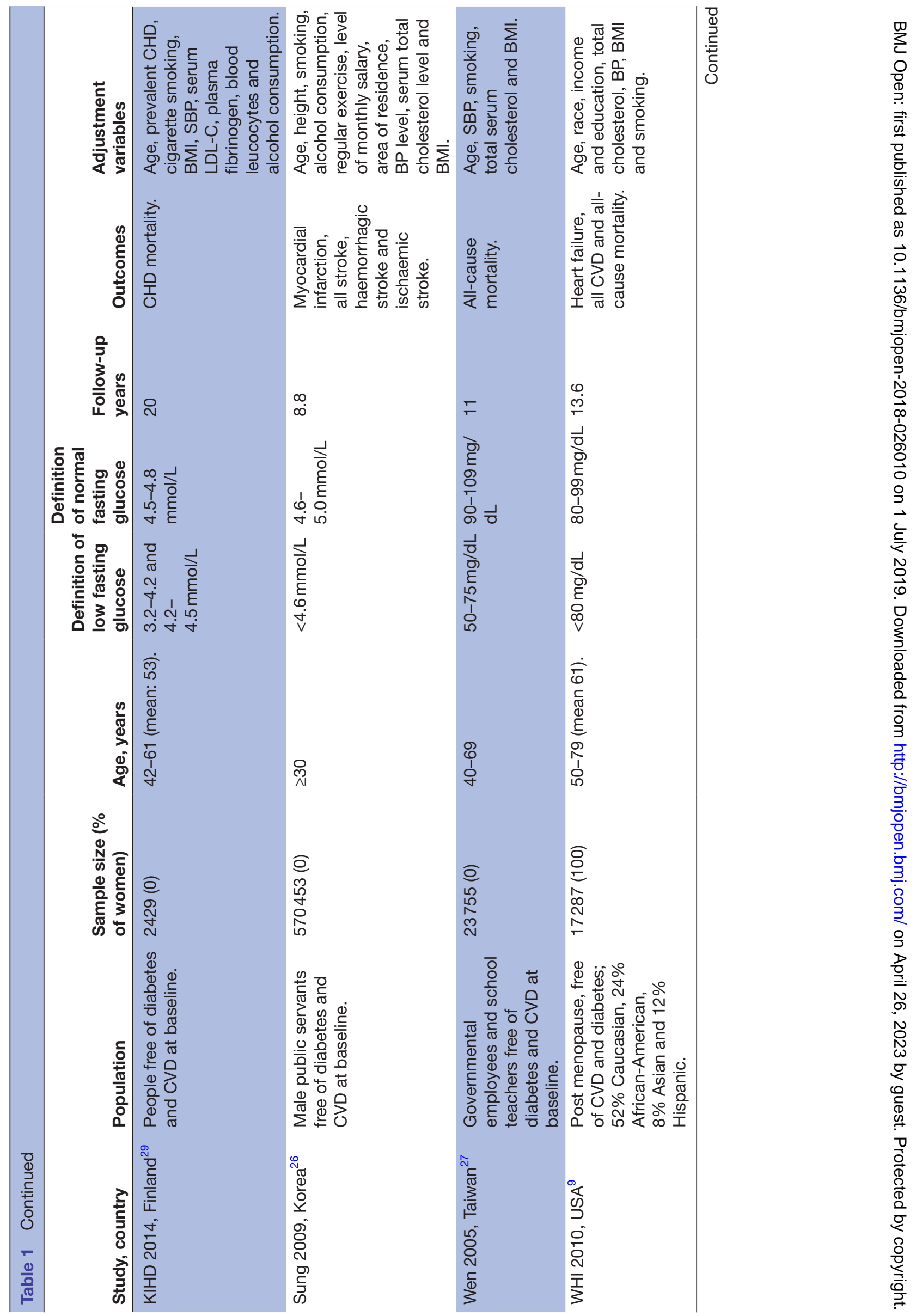




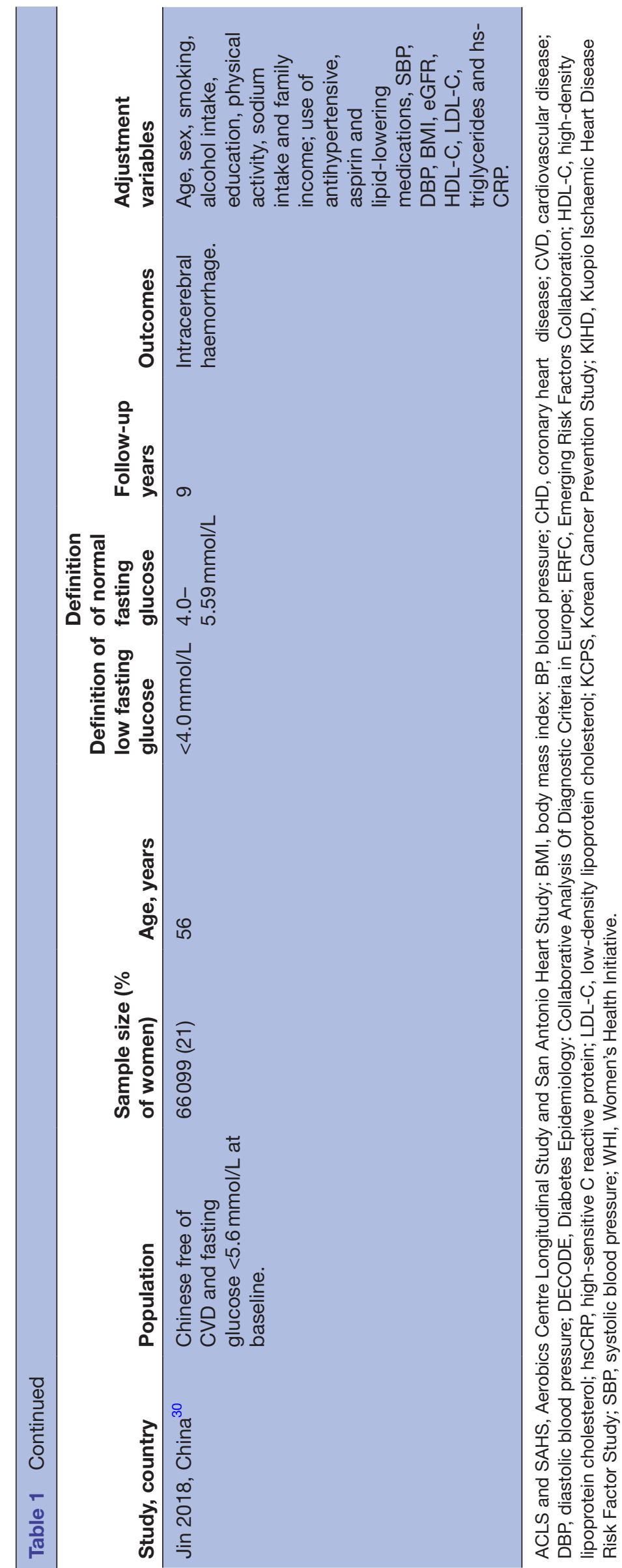

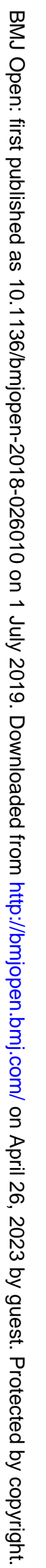




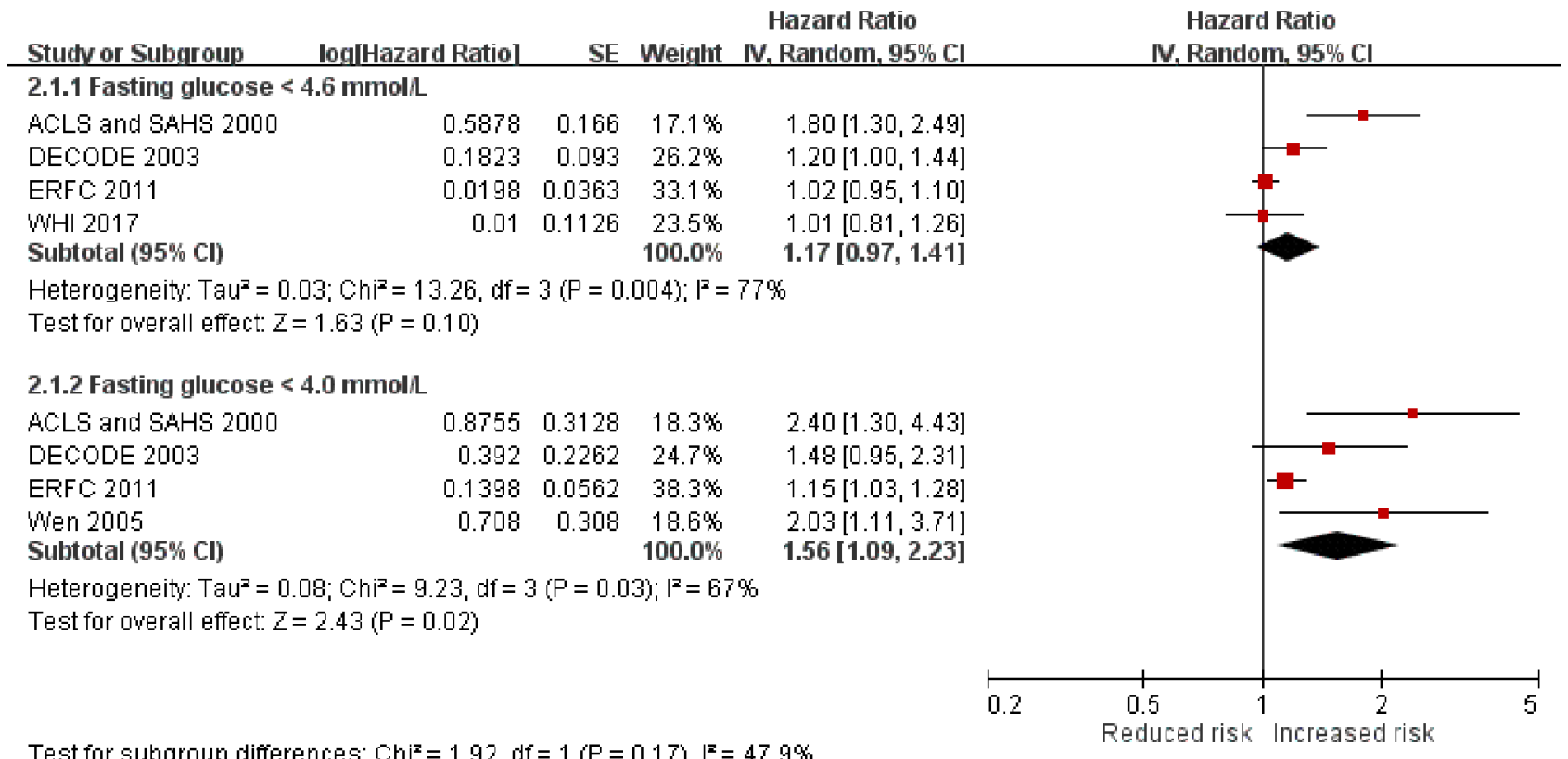

Figure 2 Association of baseline low fasting glucose $(<4.6 \mathrm{mmol} / \mathrm{L}$ and $<4.0 \mathrm{mmol} / \mathrm{L}$, respectively) and risk of all-cause mortality.

\section{DISCUSSION}

In this meta-analysis of 11 articles that included 129 prospective studies of generally good quality, consisting of over 2.6 million individuals without diabetes mellitus and cardiovascular disease at baseline, we found that people with a baseline fasting glucose $<4.0 \mathrm{mmol} / \mathrm{L}$ had an increased risk of all-cause mortality $56 \%$ greater than those with a normal baseline fasting glucose. We also found that the risks for major adverse cardiovascular events, stroke and ischaemic stroke were higher in people with baseline fasting glucose $<4.0 \mathrm{mmol} / \mathrm{L}$. The less stringent definition of low fasting glucose using $<4.6 \mathrm{mmol} / \mathrm{L}$ as cut-off was not associated with increased risk of any endpoints. The size of this study and inclusion of only prospectively collected data strengthened the robustness of our findings. In addition, all studies included in our meta-analysis reported a multivariate adjusted HR, which potentially mitigated the possibility of known confounding influencing our results. Still, a meta-analysis based on observational studies cannot prove causality.

During our literature search, there was not a consistent definition of low fasting glucose level among articles. Although some articles described the outcomes of major adverse cardiovascular events, stroke or mortality at low fasting glucose levels, the definition of low fasting glucose concentration was higher than the stringent cut-off levels $(<4.6 \mathrm{mmol})$ used in the current meta-analysis, and we excluded those studies from our analyses. ${ }^{10} 3132$ Fallen blood glucose levels trigger a sequence of physiological effects to maintain glucose homeostasis in healthy individuals. When blood glucose level decreases to a glycaemic threshold of $4.6 \mathrm{mmol} / \mathrm{L}$, insulin secretion starts to decrease and utilisation of glucose reduced. ${ }^{12}{ }^{14}$ When blood glucose concentration falls below the threshold of $4.0 \mathrm{mmol} / \mathrm{L}$, various counter-regulatory hormones, such as catecholamine, glucagon, cortisol and growth hormone, are secreted to compromise hypoglycaemia. ${ }^{13}$ Therefore, we used $<4.6 \mathrm{mmol} / \mathrm{L}$ and $<4.0 \mathrm{mmol} / \mathrm{L}$, respectively, as cut-off levels to analyse the influence of low fasting blood glucose in the general population.

The mechanism for low fasting glucose level conferring harmful effects may be related to the activation of counter-regulatory hormones, especially epinephrine. ${ }^{33}$ Such a hormone stimulates glucose production and inhibits glucose clearance when hypoglycaemia occurs and could provide enough energy to various organs, especially the brain, under stress. However, $Q$ wave to $T$ wave (QT) interval prolongation also occurs, caused mainly by sympathoadrenal stimulation due to higher epinephrine levels during hypoglycaemia. ${ }^{34}$ For instance, a previous study on insulin-induced hypoglycaemia in healthy individuals showed that changes in $\mathrm{R}$ and $\mathrm{T}$ waves were associated with counter-regulatory adrenergic activation, with elevations in norepinephrine and epinephrine. ${ }^{34}$ This acquired long QT interval syndrome and $\mathrm{T}$ wave abnormality would affect ventricular repolarisation and increase risk of ventricular arrhythmia, ${ }^{36}$ as shown in a study of non-diabetic men with a median follow-up of 23.3 years, in which fasting glucose concentration was inversely related to incident risk of ventricular arrhythmias. ${ }^{37}$ As such, an increased risk of sudden cardiac death related to ventricular arrhythmias ${ }^{36}$ due to low fasting blood glucose levels could explain increased all-cause mortality in our meta-analysis. Although mortality related to cancer could be a concern, studies that analysed the relationship between glucose level and cancer incidence did not show low fasting blood glucose level to be related to increased risk of cancer. ${ }^{1838}$ 
(A)

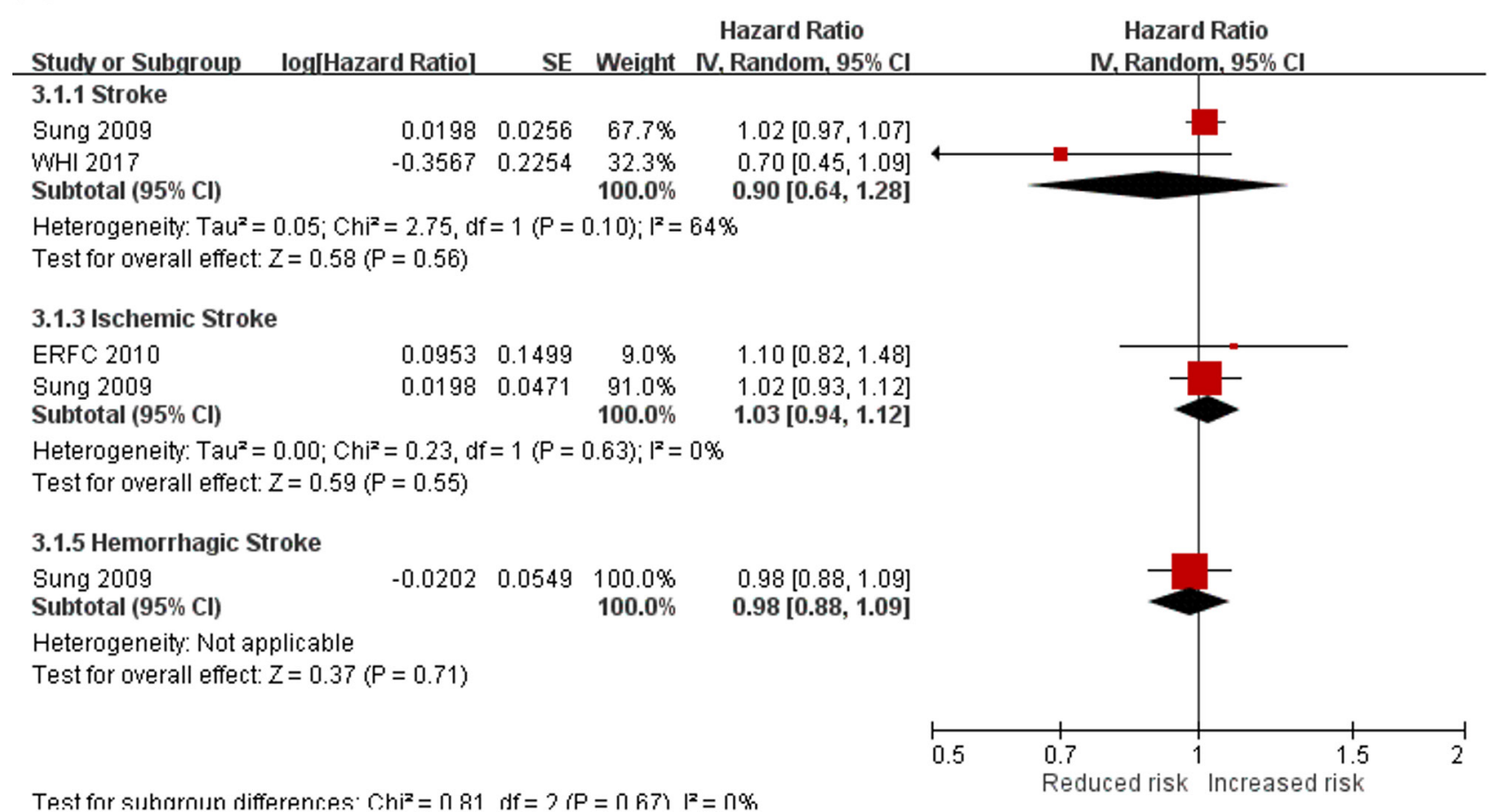

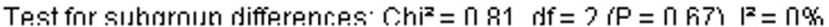

(B)

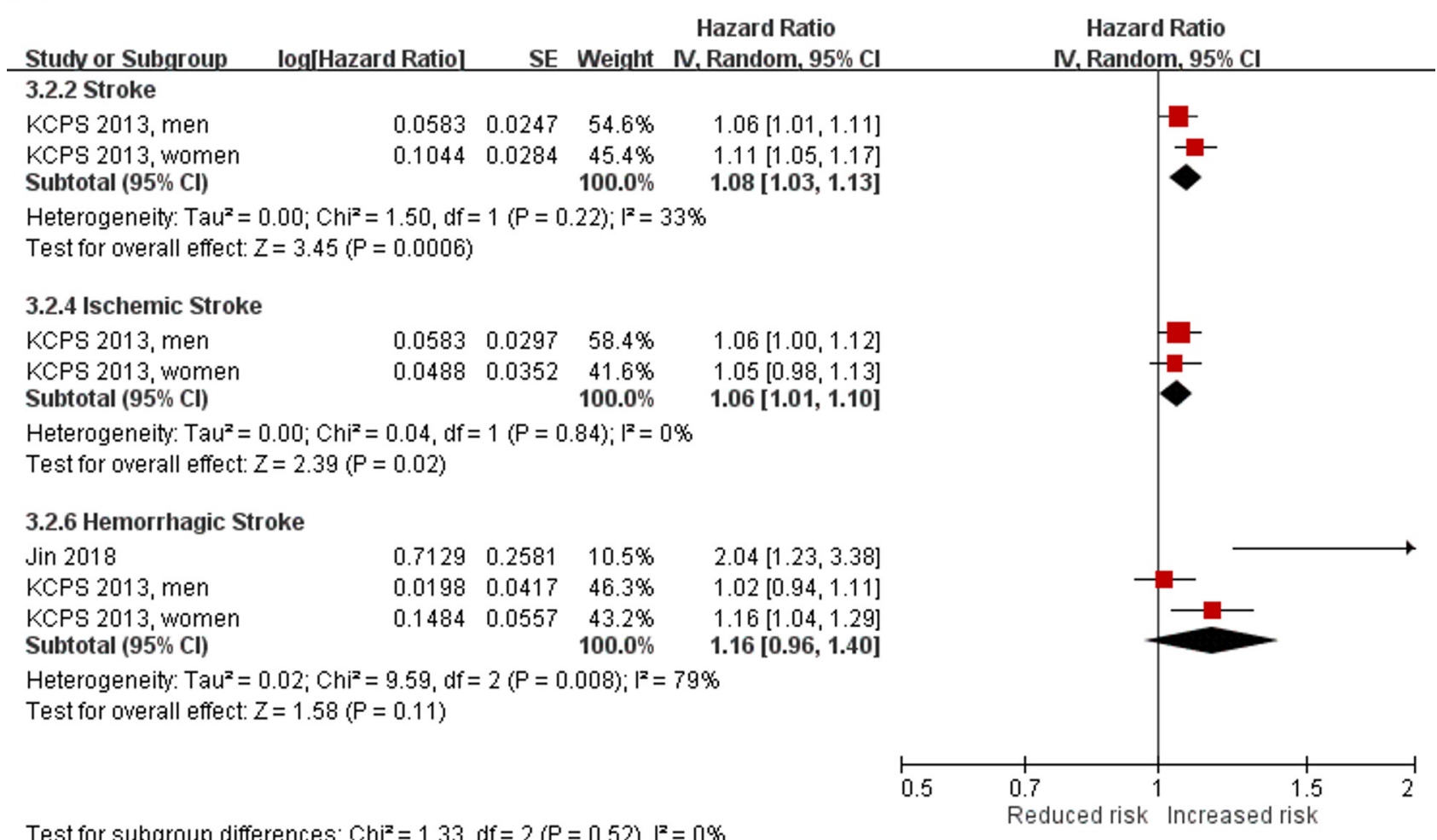

Figure 3 Association of baseline low fasting glucose $(<4.6 \mathrm{mmol} / \mathrm{L}$ and $<4.0 \mathrm{mmol} / \mathrm{L}$, respectively $)$ and risk of stroke, ischaemic stroke and haemorrhagic stroke.

Brain glucose concentration has a linear relationship with blood glucose concentration. ${ }^{39}$ Since the major energy source of the brain is glucose, hypoglycaemia may damage the brain and cause stroke-like symptoms. ${ }^{40}$ Brain imaging changes could be observed if severe long-term hypoglycaemia occurs. ${ }^{40} 41$ Also, arrhythmia caused by hypoglycaemia may increase stroke risk. ${ }^{36}$

There have been some systematic reviews and meta-analyses exploring the association of hypoglycaemia and mortality/cardiovascular disease. ${ }^{18}{ }^{42}$ Goto 
(A)

Hazard Ratio Hazard Ratio

Study or Subgroup log[Hazard Ratio]

SE Weight IV, Random, $95 \% \mathrm{Cl}$

IV, Random, $95 \% \mathrm{Cl}$

4.1.1 Major adverse cardiovascular events

WHI 2017

$-0.0408 \quad 0.1125 \quad 100.0 \%$

$0.96[0.77,1.20]$

Subtotal $(95 \% \mathrm{CI})$

$100.0 \%$

$0.96[0.77,1.20]$

Heterogeneity: Not applicable

Test for overall effect: $Z=0.36(P=0.72)$

4.1.3 Coronary heart disease

ERFC 2010

KIHD 2014

$0.0583 \quad 0.0613 \quad 35.4 \%$

$\begin{array}{lll}0.2231 & 0.1294 & 16.9 \%\end{array}$

Sung 2009

$0.0953 \quad 0.0486 \quad 40.1 \%$

WHI 2017

$-0.4155 \quad 0.218$

$40.1 \%$
$7.5 \%$

$100.0 \%$

Heterogeneity: Tau $^{2}=0.01 ; \mathrm{Chi}^{2}=6.58, \mathrm{df}=3(\mathrm{P}=0.09) ; \mathrm{I}^{2}=54 \%$

Test for overall effect: $Z=1.01(P=0.31)$

4.1.5 Cardiovascular mortality

ACLS and SAHS 2000

DECODE 2003

ERFC 2011

$\begin{array}{lll}0.6931 & 0.2606 & 23.5 \%\end{array}$

$\begin{array}{lll}0.2624 & 0.1339 & 34.9 \%\end{array}$

$-0.0619 \quad 0.0337 \quad 41.6 \%$

$100.0 \%$

$2.00[1.20,3.33]$

$1.30[1.00,1.69]$

$0.94[0.88,1.00]$

Subtotal $(95 \% \mathrm{Cl})$

$1.26[0.87,1.83]$

Heterogeneity: Tau $^{2}=0.09 ; \mathrm{Chi}^{2}=13.36, \mathrm{df}=2(\mathrm{P}=0.001) ; \mathrm{I}^{2}=85 \%$

Test for overall effect: $Z=1.20(P=0.23)$

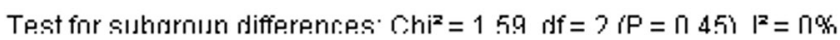

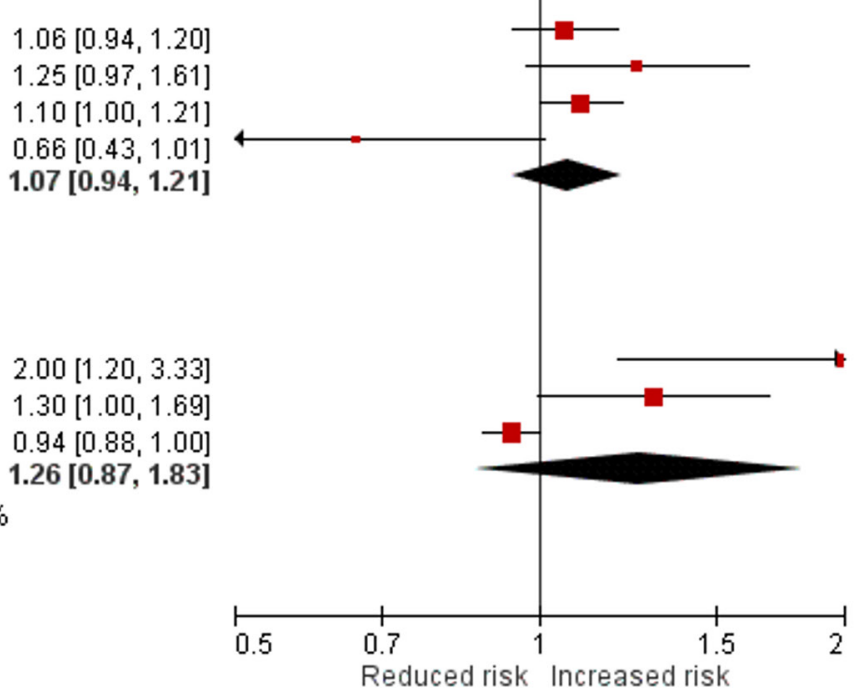

(B)

Hazard Ratio

Hazard Ratio

\begin{tabular}{lrrr} 
Studv or Subgroup & loglHazard Ratiol & SE & Weight \\
\hline 4.2.2 Major adverse car diovascular events & & \\
ERFC 2014 & 0.077 & 0.0496 & $5.4 \%$ \\
KCPS 2013, men & 0.0392 & 0.0149 & $59.9 \%$ \\
KCPS 2013, women & 0.0583 & 0.0196 & $34.6 \%$ \\
Subtotal (95\% Cl) & & $100.0 \%$ \\
Heterogeneity: Tau ${ }^{2}=0.00 ; \mathrm{Chi}^{2}=0.97, \mathrm{df}=2(\mathrm{P}=0.62) ;\left.\right|^{2}=0 \%$ \\
Test for overall effect: $Z=4.15(\mathrm{P}=0.0001)$
\end{tabular}

\subsubsection{Coronary heart disease}

ERFC 2010

KCPS 2013, men

KCPS 2013, women

KIHD 2014

Subtotal $(95 \% \mathrm{CI})$

$\begin{array}{rrr}0.1044 & 0.0532 & 24.1 \% \\ 0 & 0.0208 & 41.3 \% \\ -0.0513 & 0.0391 & 31.1 \% \\ 0.2776 & 0.1912 & 3.5 \% \\ & & \mathbf{1 0 0 . 0 \%}\end{array}$

$1.11[1.00,1.23]$

$1.00[0.96,1.04]$

$0.95[0.88,1.03]$

$1.32[0.91,1.92]$

$1.02[0.95,1.10]$

Heterogeneity: $\mathrm{Tau}^{2}=0.00 ; \mathrm{Chi}^{2}=7.64, \mathrm{df}=3(\mathrm{P}=0.05) ; \mathrm{I}^{2}=61 \%$

Test for overall effect: $Z=0.51(P=0.61)$

\subsubsection{Cardiovascular mortality \\ ACLS and SAHS 2000 \\ DECODE 2003 \\ ERFC 2011 \\ Subtotal $(95 \% \mathrm{Cl})$ \\ Heterogeneity: $\operatorname{Tau}^{2}=0.12 ; \mathrm{Chi}^{2}=4.52, \mathrm{df}=2(\mathrm{P}=0.10) ; \mathrm{I}^{2}=56 \%$ \\ Test for owerall effect: $Z=1.47(P=0.14)$}

$1.08[0.98,1.19]$

$1.04[1.01,1.07]$

$1.06[1.02,1.10]$

$1.05[1.03,1.07]$

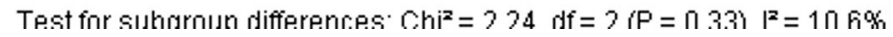

$3.30[1.30,8.38]$

$1.25[0.60,2.60]$

$1.18[0.99,1.41]$

$1.47[0.88,2.44]$ IV. Random, $95 \% \mathrm{Cl}$

Figure 4 Association of baseline low fasting glucose $(<4.6 \mathrm{mmol} / \mathrm{L}$ and $<4.0 \mathrm{mmol} / \mathrm{L}$, respectively) and risk of major adverse cardiovascular events, coronary heart disease and cardiovascular mortality. 
et $a t^{42}$ found that hypoglycaemia was associated with a higher risk of cardiovascular disease in patients with diabetes, and Yeh et al found that hypoglycaemia was a risk factor for adverse vascular events and mortality across different populations. ${ }^{18}$ The novelty of the current meta-analysis we conducted is we only included studies enrolling people without diabetes and cardiovascular disease at baseline, and therefore, the majority of studies included in our meta-analysis were not included in the previously published two meta-analyses mentioned above. ${ }^{18} 42$ Although the detrimental effects of hypoglycaemia are well established in people with diabetes or critical illness, ${ }^{1842}$ this is the first met-analysis, to our knowledge, to show that low fasting glucose (ie, $<4.0 \mathrm{mmol} / \mathrm{L}$ ) is associated with increased risks of all-cause mortality and stroke in people without baseline diabetes or cardiovascular disease. Low fasting glucose concentration found in people without diabetes and cardiovascular disease is not typically regarded as a marker of potential danger for future mortality and cardiovascular disease. However, the current meta-analysis suggests that non-diabetic people with a fasting glucose $<4.0 \mathrm{mmol} / \mathrm{L}$ may be at future higher risk of mortality and stroke, and therefore might merit a more comprehensive evaluation and regular follow-up.

Our study has several limitations. First, all included articles used baseline glucose levels at the time of study enrolment. Whether individuals with low fasting glucose level at the time of enrolment had persistently low fasting plasma glucose values is not known. Second, although individuals in our meta-analysis were not diabetic patients with iatrogenic hypoglycaemia, the reason for the low concentrations of glucose in the low fasting blood glucose population was not established. Whether these individuals had hyperinsulinaemia, insulin resistance, poor nutrition or liver dysfunction ${ }^{43}$ leading to hypoglycaemia could not be determined in most of the included articles. Potential confounders adjusted in one study did not change its results. ${ }^{8}$ Third, the definition of low fasting blood glucose varied across enrolled studies. We used cut-off values of fasting glucose according to the threshold physiological responses of endogenous adjustment to maintain glucose homeostasis. Since studies were excluded if their cut-off level of low fasting glucose was higher than the stringent level (ie, $4.6 \mathrm{mmol} / \mathrm{L}$ ) used in this meta-analysis, only limited studies were included for the pooled analysis of each endpoint.

\section{Conclusions and implications}

Our study suggests that about $5.2 \%$ of people without diabetes and cardiovascular disease at baseline have fasting glucose levels of $<4.0 \mathrm{mmol} / \mathrm{L}$, and these individuals, over a 14 -year period, harbour a $56 \%$ greater hazard of all-cause mortality, as compared with individuals with a normal glucose level. While hypoglycaemia typically manifests with symptoms, and a low fasting glucose level in the general population is usually asymptomatic, when a low fasting glucose is observed during a routine medical examination for people without diabetes and cardiovascular disease, it may be worthwhile to mention to those with a fasting glucose $<4.0 \mathrm{mmol} / \mathrm{L}$ that they might be at increased long-term risks for all-cause mortality, stroke and cardiovascular events. When fasting glucose $<4.0 \mathrm{mmol} / \mathrm{L}$ is discovered, a comprehensive survey of potential underlying causes, periodic blood glucose level evaluation and cardiac rhythm follow-up might be prudent.

\section{Author affiliations}

${ }^{1}$ Department of Nephrology, Chinru Clinic, Taipei, Taiwan

${ }^{2}$ Department of Neurology, University of California System, Los Angeles, California, USA

${ }^{3}$ School of Medicine, Johns Hopkins University, Baltimore, Maryland, USA

${ }^{4}$ College of Public Health, National Taiwan University, Taipei, Taiwan

${ }^{5}$ Institute of Population Health Sciences, National Health Research Institutes,

Zhunan, Taiwan

${ }^{6}$ Department of Neurology, Chang Gung University, Kwei-Shan, Taoyuan, Taiwan ${ }^{7}$ Department of Neurology, University of California System, San Francisco, California, USA

Contributors H-WL: acquisition of data, analysis and interpretation of data and wrote the first draft. JS: analysis and interpretation of data and critical revision of manuscript for intellectual content. H-CY: critical revision of manuscript for intellectual content. C-HSC: acquisition of data and critical revision of manuscript for intellectual content. Y-LW: acquisition of data and analysis and interpretation of data. ML: study concept and design, acquisition of data, analysis and interpretation of data and critical revision of manuscript for intellectual content. B0: study supervision and critical revision of manuscript for intellectual content.

Funding This work was supported by Ministry of Science and Technology, Taiwan, grant number: MOST105-2628-B-182-008-MY2 and Chang Gung Memorial Hospital, Taiwan, grant numbers: CORPG6D0101, CORPG6D0102 and CORPG6D0103.

Disclaimer The sponsors played no role in the study design, data collection and analysis, or decision to submit the article for publication.

Competing interests None declared.

Patient consent for publication Not required.

Provenance and peer review Not commissioned; externally peer reviewed.

Data sharing statement № additional data are available.

Open access This is an open access article distributed in accordance with the Creative Commons Attribution Non Commercial (CC BY-NC 4.0) license, which permits others to distribute, remix, adapt, build upon this work non-commercially, and license their derivative works on different terms, provided the original work is properly cited, appropriate credit is given, any changes made indicated, and the use is non-commercial. See: http://creativecommons.org/licenses/by-nc/4.0/.

\section{REFERENCES}

1 Rao Kondapally Seshasai S, Kaptoge S, Thompson A, et al. Diabetes mellitus, fasting glucose, and risk of cause-specific death. $N$ Engl J Med 2011;364:829-41.

2 Rawshani A, Rawshani A, Franzén S, et al. Mortality and cardiovascular disease in type 1 and type 2 diabetes. N Engl J Med 2017;376:1407-18.

3. Lee M, Saver JL, Hong KS, et al. Effect of pre-diabetes on future risk of stroke: meta-analysis. BMJ 2012;344:e3564.

4. Huang Y, Cai X, Mai W, et al. Association between prediabetes and risk of cardiovascular disease and all cause mortality: systematic review and meta-analysis. BMJ 2016;355:i5953.

5 Shrayyef M, Gerich J. Normal glucose homeostasis. Poretsky I, ed. Principle of diabetes mellitus. 2nd ed.. New york: Springer, 2010:19-35.

6. Gerstein HC, Miller ME, Byington RP, et al. Effects of intensive glucose lowering in type 2 diabetes. $N$ Engl J Med 2008;358:2545-59.

7. Balkau B, Bertrais S, Ducimetiere $P$, et al. Is there a glycemic threshold for mortality risk? Diabetes Care 1999;22:696-9. 
8. Wei M, Gibbons LW, Mitchell TL, et al. Low fasting plasma glucose level as a predictor of cardiovascular disease and all-cause mortality. Circulation 2000;101:2047-52.

9. Mongraw-Chaffin M, LaCroix AZ, Sears DD, et al. A prospective study of low fasting glucose with cardiovascular disease events and all-cause mortality: The Women's Health Initiative. Metabolism 2017;70:116-24.

10. Lawes CM, Parag V, Bennett DA, et al. Blood glucose and risk of cardiovascular disease in the Asia Pacific region. Diabetes Care 2004;27:2836-42.

11 Workgroup on Hypoglycemia, American Diabetes Association. Defining and reporting hypoglycemia in diabetes: A report from the american diabetes association workgroup on hypoglycemia. Diabetes Care 2005;28:1245-9.

12. Gerich J, Cryer P, Rizza R. Hormonal mechanisms in acute glucose counterregulation: the relative roles of glucagon, epinephrine, norepinephrine, growth hormone, and cortisol. Metabolism 1980;29:1164-75.

13 Sprague JE, Arbeláez AM. Glucose counterregulatory responses to hypoglycemia. Pediatr Endocrinol Rev 2011;9:463-73.

14. Schwartz NS, Clutter WE, Shah SD, et al. Glycemic thresholds for activation of glucose counterregulatory systems are higher than the threshold for symptoms. J Clin Invest 1987;79:777-81.

15. Moher D, Liberati A, Tetzlaff J, et al. Preferred reporting items for systematic reviews and meta-analyses: the PRISMA statement. BMJ 2009;339:b2535.

16. Harris RP, Helfand M, Woolf SH, et al. Current methods of the us preventive services task force: a review of the process. Am J Prev Med 2001;20:21-35.

17. Lee $\mathrm{M}$, Saver JL, Chang $\mathrm{KH}$, et al. Low glomerular filtration rate and risk of stroke: meta-analysis. BMJ 2010;341:c4249.

18. Yeh JS, Sung SH, Huang HM, et al. Hypoglycemia and risk of vascular events and mortality: a systematic review and metaanalysis. Acta Diabetol 2016;53:377-92.

19. Rücker G, Schwarzer G, Carpenter JR, et al. Undue reliance on I(2) in assessing heterogeneity may mislead. BMC Med Res Methodol 2008;8:79.

20. Higgins JP, Thompson SG, Deeks JJ, et al. Measuring inconsistency in meta-analyses. BMJ 2003;327:557-60.

21. Higgins JP, Thompson SG. Quantifying heterogeneity in a metaanalysis. Stat Med 2002;21:1539-58.

22 Higgins J, Green S. Cochrane handbook for systematic reviews of interventions version 5.1.0. 2011. The Cochrane Collaboration (Updated Mar 2011).

23. Di Angelantonio E, Gao P, Khan H, et al. Glycated hemoglobin measurement and prediction of cardiovascular disease. JAMA 2014;311:1225-33.

24. Sarwar N, Gao P, Seshasai SR, et al. Diabetes mellitus, fasting blood glucose concentration, and risk of vascular disease: a collaborative meta-analysis of 102 prospective studies. Lancet 2010;375:2215-22.

25 DECODE Study Group, European Diabetes Epidemiology Group. Is the current definition for diabetes relevant to mortality risk from all causes and cardiovascular and noncardiovascular diseases? Diabetes Care 2003;26:688-96.
26. Sung J, Song YM, Ebrahim S, et al. Fasting blood glucose and the risk of stroke and myocardial infarction. Circulation 2009;119:812-9.

27. Wen CP, Cheng TY, Tsai SP, et al. Increased mortality risks of pre-diabetes (impaired fasting glucose) in Taiwan. Diabetes Care 2005;28:2756-61.

28. Park C, Guallar E, Linton JA, et al. Fasting glucose level and the risk of incident atherosclerotic cardiovascular diseases. Diabetes Care 2013;36:1988-93.

29. Kurl S, Zaccardi F, Onaemo VN, et al. Association between HOMA$\mathrm{IR}$, fasting insulin and fasting glucose with coronary heart disease mortality in nondiabetic men: a 20-year observational study. Acta Diabetol 2015;52:183-6.

30 Jin C, Li G, Rexrode KM, et al. Prospective study of fasting blood glucose and intracerebral hemorrhagic risk. Stroke 2018;49:27-33.

31 Brutsaert EF, Shitole S, Biggs ML, et al. Relations of postload and fasting glucose with incident cardiovascular disease and mortality late in life: The cardiovascular health study. J Gerontol A Biol Sci Med Sci 2016;71:370-7.

32. Chien $\mathrm{KL}$, Lee $\mathrm{BC}$, Lin $\mathrm{HJ}$, et al. Association of fasting and postprandial hyperglycemia on the risk of cardiovascular and all-cause death among non-diabetic Chinese. Diabetes Res Clin Pract 2009;83:e47-e50.

33. Lee JJ, Khoury N, Shackleford AM, et al. Dissociation between hormonal counterregulatory responses and cerebral glucose metabolism during hypoglycemia. Diabetes 2017;66:2964-72.

34. Laitinen $\mathrm{T}$, Lyyra-Laitinen $\mathrm{T}$, Huopio $\mathrm{H}$, et al. Electrocardiographic alterations during hyperinsulinemic hypoglycemia in healthy subjects. Ann Noninvasive Electrocardiol 2008;13:97-105.

35. Robinson RT, Harris ND, Ireland RH, et al. Mechanisms of abnormal cardiac repolarization during insulin-induced hypoglycemia. Diabetes 2003;52:1469-74.

36. Tse G, Yan BP. Traditional and novel electrocardiographic conduction and repolarization markers of sudden cardiac death. Europace 2017;19:712-21.

37. Zaccardi F, Webb DR, Kurl S, et al. Inverse association between fasting plasma glucose and risk of ventricular arrhythmias. Diabetologia 2015;58:1797-802

38. Jee SH, Ohrr H, Sull JW, et al. Fasting serum glucose level and cancer risk in Korean men and women. JAMA 2005;293:194-202.

39. van de Ven KC, van der Graaf M, Tack CJ, et al. Steady-state brain glucose concentrations during hypoglycemia in healthy humans and patients with type 1 diabetes. Diabetes 2012;61:1974-7.

40. Yong AW, Morris Z, Shuler K, et al. Acute symptomatic hypoglycaemia mimicking ischaemic stroke on imaging: a systemic review. BMC Neurol 2012;12:139.

41. Fujioka M, Okuchi K, Hiramatsu KI, et al. Specific changes in human brain after hypoglycemic injury. Stroke 1997;28:584-7.

42. Goto A, Arah OA, Goto M, et al. Severe hypoglycaemia and cardiovascular disease: systematic review and meta-analysis with bias analysis. BMJ 2013;347:f4533.

43. Christman AL, Lazo M, Clark JM, et al. Low glycated hemoglobin and liver disease in the U.S. population. Diabetes Care 2011;34:2548-50. 